\title{
Catégories et politiques du religieux en Chine
}

\section{Vincent Goossaert et David Palmer}

\section{(2) OpenEdition}

Journals

Édition électronique

URL : http://journals.openedition.org/assr/17613

DOI : 10.4000/assr.17613

ISSN : 1777-5825

Éditeur

Éditions de l'EHESS

Édition imprimée

Date de publication : 1 octobre 2008

Pagination : 9-11

ISBN : 978-2-7132-2192-7

ISSN : 0335-5985

Référence électronique

Vincent Goossaert et David Palmer, "Catégories et politiques du religieux en Chine », Archives de sciences sociales des religions [En ligne], 144 | octobre-décembre 2008, mis en ligne le 01 octobre 2011 consulté le 19 avril 2019. URL : http://journals.openedition.org/assr/17613 ; DOI : 10.4000/assr.17613 


\section{Vincent Goossaert, David Palmer}

\section{Catégories et politiques du religieux en Chine}

Depuis les années quatre-vingt-dix, on observe un essor considérable, dans toutes les disciplines académiques - histoire, anthropologie, sciences politiques notamment - des études sur la religion dans le monde chinois moderne et contemporain qui rendent compte des manifestations de plus en plus variées et globalisées de la vitalité religieuse chinoise. Seule la sociologie des religions est restée relativement en retrait. Les comparaisons avec d'autres mondes culturels sont assez rares, et le cas de la Chine n'a pas encore trouvé sa place dans les débats théoriques sur la sécularisation, la transformation des rapports entre religion et politique en ultra-modernité, comme sur d'autres thèmes d'intérêt global. Parmi diverses initiatives très récentes qui ont eu pour objet de faciliter les rencontres entre les sociologues du religieux et les spécialistes du terrain chinois ${ }^{1}$, on peut mentionner le colloque "Religion and Social Integration in Chinese Societies. Exploring Sociological Approaches to the Study of Religion in the Chinese World " ${ }^{2}$, qui s'est tenu à la Chinese University of Hong Kong les 28-30 juin 2007. Les articles qui suivent en sont issus.

L'un des enjeux de ce colloque était de cerner les modes de sécularisation spécifiques au monde chinois, et plus particulièrement les interactions entre le sécularisme (la laïcité "dure ») comme projet politique, porté depuis plus d'un siècle par plusieurs générations de leaders politiques de tous bords, et les processus de sécularisation propres à la société (Yang, 2008 ; Ji, 2008 ; Ji, à paraître), tous deux tendant chacun à leur façon à définir un religieux de périmètre réduit. Plus spécifiquement, ces interactions mettent en évidence la production continue des catégories de gestion et d'analyse du religieux dans l'interaction entre acteurs politiques, universitaires et idéologues.

1. Il faut notamment signaler les initiatives de Yang Fenggang de Purdue University : voir son site http://www.cla.purdue.edu/sociology/religion/.

2. Colloque organisé par le Chung Chi College Centre for the Study of Religion and Chinese Society (CUHK), l'École française d'Extrême-Orient (EFEO) et le Groupe Sociétés, Religions, Laïcités (EPHE-CNRS). 
Plutôt que d'attaquer frontalement la redéfinition moderne de la religion en Chine $^{3}$, notamment au travers des cinq religions officiellement reconnues (et étroitement régulées) en République Populaire - bouddhisme, taoïsme ${ }^{4}$, islam, protestantisme, catholicisme - nous avons choisi ici d'examiner des objets rejetés hors de la catégorie « religion » pour examiner comment ce « reste » (ce religieux qui n'est plus reconnu comme religieux) est traité par les politiques et les savants, les uns en étroite interaction avec les autres. David Ownby et David Palmer étudient les devenirs de la catégorie «secte» dans les travaux scientifiques occidentaux et chinois et dans les discours politiques, tandis que Fang Ling et Vincent Goossaert examinent les « coutumes » et " superstitions » des pratiques funéraires.

L'un des soucis partagés par les quatre auteurs est de dépasser les frontières des régimes (impérial, nationaliste, communiste) qui l'on retrouve tant dans l'historiographie que dans le monde réel. Les observateurs de la religion dans le monde chinois considèrent souvent que la République Populaire de Chine, la République de Chine à Taiwan et les régimes coloniaux et post-coloniaux (comme Hong Kong) ont chacun leur propre trajectoire en terme de sécularisation, de définition normative et de gestion politique du religieux. Cependant les logiques de réinvention du religieux en domaines distincts - la religion, la superstition, les sectes, les rites et coutumes - se déploient de façon continue depuis un siècle au-delà des changements politiques, et les interactions entre ces divers régimes en matière de modèle de gestion du religieux sont de plus en plus intenses; ainsi, la République Populaire de Chine invoque volontiers les exemples d'autres pays en termes de réforme funéraire et de lutte contre les « sectes ». Les catégories sont mouvantes tant du fait des changements de politique interne, comme à la suite de l'affaire du Falungong en 1999 (Ownby, 2008), que de l'évolution du discours global sur la religion - la promotion du "patrimoine culturel intangible » par l'Unesco depuis 2003 contribuant à légitimer et reclassifier politiquement certains aspects des «coutumes " religieuses (rites, festivals) chinoises.

Outre sa contribution aux études sur le religieux chinois, nous espérons que ce dossier contribuera à l'étude sociologique et historique des catégories par lesquelles le religieux est traité dans les sociétés modernes, catégories que les chercheurs utilisent sans pouvoir maîtriser leur usage politique et social.

3. Pour une analyse globale, voir : David Palmer, Vincent Goossaert, La question religieuse en Chine moderne (ouvrage en cours d'édition, à paraître en anglais et en français); pour une courte synthèse, voir Goossaert (2007).

4. Sur les multiples réinventions de la catégorie " taoïsme ", voir Palmer et Liu (à parâitre). 


\section{Bibliographie}

GoOsSAERT Vincent, 2007, "L'invention des "religions" en Chine moderne ", in Cheng A., (éd.), La pensée en Chine aujourd'hui, Paris, Gallimard, pp. 185-213.

GoossaerT Vincent, Ownby David, (éds.), 2008, special issue "Mapping Charisma in Chinese Religion ", Nova Religio, 12-2.

Ji Zhe, 2008, "Secularization as Religious Restructuring: Statist Institutionalization of Chinese Buddhism and Its Paradoxes ", in Yang M., (éd.), Chinese Religiosities: Afflictions of Modernity and State Formation, Berkeley, University of California Press.

Ji Zhe, à paraître, "Buddhism in the Reform-Era China: A Secularised Revival? ", in Chau A.Y., (éd.), Religion in Contemporary China: Revitalization and Innovation, Londres, Routledge.

Ownby David, 2008, Falun Gong and the Future of China, New York, Oxford University Press.

Palmer David A., LiU Xun, (éds.), à paraître, Taoism in the Twentieth Century: Between Eternity and Modernity.

YANG Mayfair Mei-hui, (éd.), 2008, Chinese Religiosities: Afflictions of Modernity and State Formation, Berkeley, University of California Press. 